University of Wollongong

Research Online

Faculty of Social Sciences - Papers (Archive) Faculty of Arts, Social Sciences \& Humanities

2014

What is good parenting? The perspectives of different professionals

Philippa M. Eve

Macquarie University

Mitchell K. Byrne

University of Wollongong, mbyrne@uow.edu.au

Cinzia R. Gagliardi,

Follow this and additional works at: https://ro.uow.edu.au/sspapers

Part of the Education Commons, and the Social and Behavioral Sciences Commons

Research Online is the open access institutional repository for the University of Wollongong. For further information contact the UOW Library: research-pubs@uow.edu.au 


\title{
What is good parenting? The perspectives of different professionals
}

\begin{abstract}
Defining parenting, and good parenting in particular, is a complex task wrought with ambiguities. This creates problems in agreeing on a standard parenting capacity assessment, particularly in relation to strengths as opposed to weaknesses. To address this lack of consensus, the current study explored the convergence and divergence of different professional groups' opinions on good parenting. A mixedmethods design was employed, with semi-structured interviews and rating scales administered to 19 professionals with experience in parenting capacity assessments. Data were analyzed using a constructivist grounded theory. The findings suggest that, in general, professionals agree on main themes of good parenting, including (1) insight, (2) willingness and ability, (3) day-to-day versus complex/longterm needs, (4) child's needs before own, (5) fostering attachment, and (6) consistency versus flexibility. Within these six categories, individual differences emerged. Theoretical and practical implications are discussed.
\end{abstract}

Keywords

perspectives, parenting, different, professionals, good

Disciplines

Education | Social and Behavioral Sciences

Publication Details

Eve, P. M., Byrne, M. K. \& Gagliardi, C. R. (2014). What is good parenting? The perspectives of different professionals. Family Court Review: an interdisciplinary journal, 52 (1), 114-127. 


\title{
What is Good Parenting? The Perspectives of Different Professionals
}

\author{
Philippa M. Eve \\ Mitchell K. Byrne* \\ Cinzia R. Gagliardi
}

Defining parenting, and that of good parenting, is a complex task wrought with ambiguities. This creates problems in agreeing on a standard parenting capacity assessment, particularly in relation to strengths as opposed to weaknesses. To address this lack of consensus, the current study explored the convergence and divergence of different professional groups’ opinions on good parenting. A mixed methods design was employed, with semi-structured interviews and rating scales administered to 19 professionals with experience in parenting capacity assessments. Data were analysed using a constructivist grounded theory. The findings suggest that in general, professionals agree on main themes of good parenting, including 1) insight; 2) willingness and ability; 3) day-to-day versus complex/long-term needs; 4) child's needs before own; 5) fostering attachment; and 6) consistency versus flexibility. Within these 6 categories, individual differences emerged. Theoretical and practical implications are discussed.

Key Words: Parenting assessment; family law; parenting capacity; professionals; child protection

\footnotetext{
* Correspondence: mbyrne@uow.edu.au
} 
The assessment of parenting capacity is a core task in child protection, and is often done in combination with risk assessments. ${ }^{1}$ Parenting capacity assessments (PCA's) are mainly used in the New South Wales (NSW) Children's Court, however, they may also form part of an overall assessment in Family Court proceedings. These assessments are done by social workers or psychologists who work for social services ${ }^{1}$, mental health nurses ${ }^{2}$, or independent assessors appointed by the court. ${ }^{3}$ All PCA's occur once a problem has been identified $^{1}$, including cases of suspected child maltreatment; environments in which parental fitness is questionable due to mental illness, alcoholism, or instability ${ }^{4}$; family dissolution matters ${ }^{5}$; or in rare cases, before birth. ${ }^{6}$ They may also be conducted when problems of a child cannot be explained, in areas such as physical injuries, developmental delays, unusual responses to parents, and non-organic failure-to-thrive. ${ }^{7}$

While PCA’s may initially be conducted for social service reasons (such as service planning for struggling parents), they are often later utilised as forensic evidence in legal decisions regarding family reunification, visitation rights, foster care decisions, and the termination of parental rights. ${ }^{8,9}$ PCA's have been found to hold considerable impact over forensic decisions ${ }^{10}$, including child custody. For example, Jamieson, Tranah, and Sheldrick ${ }^{11}$ found that in 37 child care court cases in England, assessment recommendations were wholly followed in 73 percent of cases. Furthermore, Waller and Daniel ${ }^{4}$ found that lawyers expect clear conclusions from parenting assessments, with 75 percent expecting a clear recommendation on custody and visitation decisions.

However, despite the influence of PCA's on court decisions, there is no clear consensus as to what they should include. Many different standards of practice exist ${ }^{7,8,12,13,14}$, and yet research consistently suggests that professional assessment of parenting capacity is highly divergent. ${ }^{2,9,15,16,17}$ 
There is debate in the literature as to whether a comprehensive and objective assessment of parenting capacity is possible due to the complexity of influencing factors. ${ }^{8}$ However, without any basic standardised practice, assessments are open to the individual bias of the evaluator. Furthermore, unlike risk assessments, there are currently no actuarial tools that assess parenting capacity. Currently, assessments rely on consensus-based tools ${ }^{18,19}$, based on previous and current clinical judgements, usually not validated by empirical research. ${ }^{1,10}$ Clinical judgement may produce self-fulfilling prophecies ${ }^{20}$, where rather than using vital evidence such as known risks, significant historical information, and psychological evidence ${ }^{21,22}$, first impressions and personal values guide decisions. For example, Daniel ${ }^{23}$ found that within a group of experienced social workers, different value systems had varying influences on the outcome of the same investigation.

This creates problems for the reliability of legal decisions where judges may have little formal knowledge of assessments, child development, or the effects of adult behaviours on parenting ${ }^{24}$, and thus completely rely on the recommendations from an assessment. Therefore, significant decisions may be based on potentially flawed assessments which may not have tapped into relevant areas of a parent’s capacity.,25

Furthermore, while parenting capacity assessments often include environmental factors which may encompass strengths (such as social support), they often focus on weaknesses, leading to selective bias in which strengths are minimised, discounted or even ignored. ${ }^{26,27}$ Parental strengths play an important role in the planning of interventions and enable the removal of blame from parents. ${ }^{1,27}$ This is especially important for parents who have learning difficulties or mental illness, where support could alleviate some of their parenting problems. ${ }^{28,29}$

Much of the extant literature on parenting has followed a deficit model, focusing on the outcomes of negative and negligent parenting. While there is some agreement within the 
literature about aspects of 'good parenting, ,30,31,32 the dynamic, bidirectional processes of parental characteristics, child characteristics and the wider social environment ${ }^{33,34}$ have impaired attempts to define 'good' or 'good enough' parenting in precise terms. ${ }^{35}$

Given the complexity of defining parenting, differences within a discipline or profession on how to assess parenting have been reported. ${ }^{35}$ These differences are likely to be exaggerated when comparing the opinions of individuals from different disciplines or professions. However, little research has addressed different professional groups' opinions on parenting. Given that multiple professional groups are often involved in parenting assessments, the divergence or convergence of cross professional opinion has implications for the outcomes of such assessments. Fundamentally different assumptions between the legal and mental health systems may exist, threatening the credibility and applicability of parenting capacity assessments by mental health professionals in legal contexts. ${ }^{9}$ This has perhaps promoted the 'deficits based approach' to PCA's, as obvious signs of harm are easier to quantify than evidence of 'good parental practice'. However, PCA's, by definition, need also address differences in parental "capacities” and as such research is required to explore the variability of different professional groups' perspectives on 'good parenting'. Agreement on 'good parenting' may assist the court in making decisions in the absence of clear risks to the child and contribute to the development of a standardised strengths-based assessment process that traverses the professional divide.

\section{Method}

\subsection{Design}

The study employed a mixed methods design, in which quantitative data was mapped onto qualitative data. Given the paucity of research on the qualitative differences between professional groups' conceptions of good parenting, this research was exploratory and thus a 
constructivist grounded theory (GT) method was used to analyse both qualitative and quantitative data, allowing for triangulation of results. The GT method was instructed by Charmaz ${ }^{36}$ and Strauss and Corbin. ${ }^{37}$ Participants first took part in a semi-structured interview, followed by a brief rating scale on dimensions of parenting.

\subsection{Participants}

Purposive sampling was initially employed to recruit participants with professional experience in either the construction or use of PCA's. Theoretical sampling was later used to further develop theory by challenging and elaborating on emerging categories. This ensured that the GT was conceptually rich and captured a diverse range of views. No specific sample size was identified but rather sampling continued until theoretical saturation had occurred and no new themes emerged. To achieve this, a total of 50 professionals, including magistrates, lawyers, social workers/Community Services (CS) employees, and psychologists, were approached to participate in the study. Of these, 19 consented to participate (38\%), including 5 social workers/CS workers, 5 psychologists, 5 lawyers, and 4 magistrates. Participant characteristics are detailed in Table 1.

\section{INSERT TABLE 1 ABOUT HERE}

\subsection{Measures}

Data was collected through a brief demographic questionnaire, a semi-structured interview protocol, and a brief rating scale on dimensions of parenting informed by the literature. $^{13,38,39}$

\subsection{Procedure}

A brief literature review was conducted prior to data collection, to identify themes needed to construct interviews and the rating scale. All data was collected in a single session 
in the participant's office to ensure a natural setting. Each participant provided informed consent prior to any data collection. Interview times ranged from 15 to 60 minutes (mean = 30 minutes). Whilst the same broad areas of parenting were covered in each interview through open ended questions; order, probes, and specific areas varied according to interviewees’ leads. The broad areas were prompted by the researcher only after sufficient chance was given to the interviewees to identify them independently. This was to ascertain opinions on the relative importance of these broad areas and whether participants agreed on specific aspects within each area.

Participants were also encouraged to talk about areas not identified in the interview questions. In line with the GT method, further questions were included in later interviews to investigate emerging categories. All questions were aimed at eliciting dimensions participants' considered necessary for good parenting, and the relative importance of these areas. The participants were reminded throughout to respond to questions in relation to their professional experience.

A brief rating scale on the relative importance of 8 dimensions of parenting was administered after interviews so as to not influence responses. Debriefing and time for further comments was provided at the end of data collection. Interviews were recorded and were transcribed verbatim immediately after sessions, with identifying information removed.

\subsection{Data Analysis}

Transcripts were analysed simultaneously with analysis following the constant comparison method, recommended by Strauss and Corbin ${ }^{40}$, in which data instances, cases, and categories are constantly compared with similarities and differences. Data analysis was undertaken by author PE, who kept a reflexive journal to identify biases, decisions and opinions on theory development. 
The data was systematically analysed according to coding techniques proposed by Charmaz ${ }^{36}$, including 3 levels: (1) open coding, (2) focused coding, and (3) theoretical coding. Diagrams, as recommended by Strauss and Corbin $^{40}$ and Charmaz ${ }^{36}$, were also used at different points in coding to illustrate emerging concepts and categories, and to tease out relationships.

\section{Results}

Six main categories of good parenting were identified by the 4 professional groups: (1) Insight; (2) Willingness + ability; (3) Day-to-day versus complex/long-term needs; (4) Child's needs before own; (5) Fostering attachment; and (6) Consistency versus flexibility. Whilst there was general agreement around these categories, individual differences emerged on factors within some categories including the (1) availability of resources (category 1: Insight), (2) the influence of support (category 1: Insight); (3) views on attachment (category 5: Fostering attachment) and (4) the relative importance of different parenting dimensions (category 3: Day-to-day versus complex/long-term needs). No demographic biases were found.

\subsection{Agreement among Professionals}

\subsubsection{Insight}

Insight was defined as 'an awareness of one's role as a parent, including understanding your individual child, their needs, and your ability to provide for those needs.' All participants except one psychologist, stressed concepts relating to insight. 'Insight' included 2 sub-categories, 'knowing the individual child' and 'acknowledge limitations as a parent'. 


\section{Knowing individual child}

Insight requires a parent to know their individual child, recognising and supporting their strengths and weaknesses. As one lawyer said:

“There is no easy formula, every child is different. I mean even in one family, you've got such a range of interests and differences in children and it's not easy to negotiate what those differences are and how best to meet a child's needs...You know, not everyone is going to be a piano player, not everyone's going to like music, not everyone's going to be good at maths. You don't know what the kids are good at or bad at, and I don't think you should force that. I think what you need to do is be intuitive and ... encouraging the things that they are good at and allowing them opportunities to develop their skills.”

Participants also recognised that different children respond to different styles of parenting and discipline. As one lawyer said:

“The importance of routine is dependent on the individual child...and I think kids with autism must have a routine."

\section{Acknowledge limitations as a parent}

Insight also requires parents to acknowledge their limitations as a parent. Parents may have problems with particular parenting skills, time limitations, or have a range of external factors which can negatively impact on their parenting capacity, (such as the absence of social/family support or mental health issues). Good parenting involves the recognition of limitations and attempts to improve on them, by changing behaviour or asking for help. As one magistrate said:

"If the parents have the level of insight then it's very encouraging because they realise then that they have limitations and that they care for their children, and they 
need to turn to areas where they can get supports...So provided they've got that insight then I think they're halfway there."

\section{Willingness + ability}

Professionals agreed that good parents need to have both a willingness to parent, and an ability to parent. This was defined as 'a parent's motivation to parent coupled with a sufficient capability to parent long-term.' All professionals but 2 (1 lawyer and 1 magistrate) talked about the relationship between willingness and ability.

\section{Willingness}

Firstly, parents must be willing to parent at all times. Part of a parent's willingness is to accept responsibility for problems and attempt to improve. This may entail attending programs to overcome their limitations, such as parenting courses, or rehabilitation for drug and alcohol related issues. Thus, willingness is also related to insight, in that parents must first recognise (insight) and then be willing to improve upon their limitations.

\section{Ability}

Similarly, parents also need to have an ability to parent. Many professionals stated that 'love is not enough', arguing that simply because someone wanted to be a good parent, did not necessarily translate to being a good parent. Parents must know the basic needs of a child, and be able to provide for those needs. Furthermore, parents need to have the ability to manage competing demands, organise the household, and have the necessary skills for behaviour management. Thus, parenting ability is also related to insight, in that parents must be able to identify a child's needs in order to be able to develop specific styles of parenting for the individual child.

This need for a combination of willingness and ability often relates to parents who have severe intellectual disabilities, who may be willing to parent, but may not have the 
ability to parent; or conversely, parents with drug and alcohol issues who may have the ability, but are not willing to address the issues affecting their parenting problems.

When referring to a specific client, the CS worker stated:

"After we finished our assessment it was, she can parent, she's just got this massive drug and alcohol problem at the moment that she wasn't willing to address. So she was able to parent, she just wasn't willing to change her lifestyle.”

\section{Day-to-day versus complex/long-term needs}

Professionals agreed that good parenting could be divided into meeting the basic, dayto-day needs of a child, and meeting the more complex, long-term needs of a child, defined as 'meeting the basic developmental needs of a child, whether they be physical, emotional, safety, discipline, or cognitive, whilst also balancing the longer term needs of a child, enabling the child to reach their potential and develop into a well-adjusted human being.'

\section{Child's needs before own}

All professionals, but 1 magistrate, stressed the necessity for parents to put their child's needs before their own. This was defined as 'a parent's ability to identify their child as a dependent person, prioritising the child's needs, which may involve sacrifice and protection'. Sacrifice and protection were subcategories. Professionals agreed that good parents are child focused, and often sacrifice their own needs in order to meet their child's needs. In doing so, they prioritise their child's needs and thus protect them from distressing emotions, situations, or conflict with another partner.

Sacrifice and protection often coincide with good parenting decisions. For example, parents may need to sacrifice the security of another partner, if that partner poses a risk to the child. As one lawyer said:

"Protecting the child against any form of abuse or neglect, whether it be sexual or physical, you have a lot of cases where mothers or fathers...they're actually aware 
that the child is being physically or sexually abused but their need for economic and emotional security for themselves overrides that, and they remain with that partner."

\section{Fostering attachment}

Every professional recognised the importance of fostering attachment as a key element in good parenting. This was defined as 'the need for caregivers to encourage bonding and attachment with a child, in order to establish security, comfort, and confidence.' All professionals agreed that attachment was developed through providing comfort, nurturing, and sensitivity towards the child.

\section{Consistency versus flexibility}

Most professionals talked about the need for a balance between consistency and flexibility, defined as 'the ability of a parent to provide consistent parenting in all regards, however at the same time remain flexible and open to change.'

\section{Consistency}

All professionals, but 1psychologist, talked about the need for parents to be consistent, through providing a stable and secure environment for their child, consistent discipline, establishing boundaries and routines, or applying consistent patterns of parenting. As one psychologist said:

"It's (consistency) probably the word I say the most during interventions! When you're dealing with any behaviour, the faster you become consistent the sooner things will improve."

\section{Flexibility}

Most professionals (excluding 3 magistrates and 1 psychologist) talked about the need for flexibility in good parenting. Flexibility could be reflected in a parent's ability to be 
receptive to ideas and advice, where by taking on advice, parents can change their behaviour or attitudes when a problem occurs. As one psychologist said:

“To be a good parent I think you've got to be dynamic, you know you can't be static, you've got to be receptive to ideas and you have to move out of your comfort zone."

\section{Disagreement among Professionals}

No significant inter-profession group differences emerged, however there were individual differences on the emphasis attributed to subcategories.

When looking at the factors impacting on parenting ability, many professionals disagreed on the availability of resources (category 1, Insight). Resources include any economic assistance, housing assistance, support related to addressing parenting limitations (such as rehabilitation centres for drug and alcohol, or parenting courses), or other support to assist parents with the care of their child (such as respite centres).

Many individuals argued that the Australian government and charitable organisations provide a great deal of resources and support to parents in need and that it was not the availability of resources that influenced parenting capacity, but rather a parent's ability to ask for help or seek assistance.

These individuals argued that factors, such as emotional vulnerabilities, may hinder a parent's ability to seek help. As one lawyer said:

“I just don't think that it's just as simple as the resources are out there, people just need to go and find them. People have vulnerabilities and they're not able to find things themselves because sometimes they don't have the emotional abilities to find the resources to make them better parents or to be able to look after themselves in order to meet their own children's needs and their own."

Other individuals argued that whilst Australia has a good welfare system compared to other countries, there are still gaps in resources available for parents. When asked whether 
they agreed with the idea that it is more about a parent's ability to seek assistance, one lawyer replied:

“Nup...Especially in relatively isolated communities... For example, family

relationships centres have such a long period of delay. There's at least 3 or 4 months.

And in a life of a child, 3 or 4 months is a very long period of time."

Individuals also disagreed on the impact of social and family support on parenting ability.

Many individuals agreed that forms of support were always beneficial to a parent, assisting parents to provide for a child's needs. As one magistrate stated:

"Provided they had that support around them I would not remove a child. Because there is one place a kid wants to be and that's in its family."

On the other hand, some individuals argued that social and family support may hinder a parent's ability. For example, extended family members such as grandparents may negatively impact on a parent's ability. As one lawyer said:

"It tends to be the paternal grandmothers and sometimes the whole extended family can be quite a toxic influence. They tend to be the grandparents that are more interfering; a lot of what happens is under pressure from the grandparents and the extended families.”

Other individuals argued that parents with a great deal of support were no longer parenting, arguing that to be a good parent, a parent must be able to parent without support. As one psychologist stated:

"If...the parenting capacity is fundamentally flawed...no amount of scaffolding is going to assist.”

This was not a universal opinion. As another CS worker argued: 
"You could say that about all people in society. People send their children to boarding schools or childcare 5 days a week and they are still considered good parents.”

Individuals also disagreed on the relative importance of different parenting dimensions (see Table 2) with scatter across and within professions. These specific findings were based on the qualitative (semi-structured interview) and quantitative data (brief rating scale).

\section{INSERT TABLE 2 ABOUT HERE}

\section{Discussion}

This study aimed to explore different professionals’ opinions on what constitutes good parenting. Six main categories of good parenting were agreed upon by the professionals, including insight; willingness and ability; day-to-day versus complex/longterm needs, child's needs before own; fostering attachment; and consistency versus flexibility.

While no professional group differences emerged, individuals disagreed on some specific areas within these categories. However, for the most part, participants agreed on the broad themes of good parenting.

It makes intuitive sense that 'insight' was identified as a main aspect of good parenting. Without understanding your role as a parent and the potential factors that may impact on it, the ability to adequately provide for your child may be limited. Previous research supports the impact of insight on parenting. Insight may function as a protective factor for child maltreatment, and may be a valuable measure in assessing parents with mental illness. ${ }^{41}$ Furthermore, the concept of insight is related to 'meta-parenting', a construct developed by Holden and Hawk. ${ }^{42}$ This is defined as 'a class of evaluative parental thought 
concerning the child-rearing domain that typically occurs before or after parent-child interactions' (p. 191). Holden and Hawk propose that meta-parenting may be associated with effective parenting, encompassing forms of anticipation, assessment, problem solving, and reflection.

The second category, 'willingness + ability', reflects the need for parents to combine parenting skills and motivation. The concept of parental willingness has been widely discussed throughout the literature. For example, Donald and Jureidini ${ }^{43}$ argued that when $^{2}$ assessing parents in cases where child maltreatment has been established, assessments should focus on parental acceptance of responsibility and acknowledgment of a need for change.

Ability is perhaps one of the most important attributes to being a good parent, in that without basic parenting skills, the ability to provide adequately for your child may be limited. Good parenting involves the demonstration of parental ability, which can be enhanced through parenting education programs. ${ }^{44}$

The third category, 'day-to-day versus complex/long-term needs' is also widely reflected within the literature. Whilst little consensus exists on the definition of a good parent, there is a general agreement on parenting as a task in meeting the child's physical, emotional, and cognitive needs on a day-to-day basis. ${ }^{1,22}$ Furthermore, this study's finding that good parents support the long-term needs of a child, is also discussed within the literature. It is generally accepted that parenting is a task of socialisation, in which children are guided by parents on values expected by society. ${ }^{45}$ Moreover, within Western society, parents are expected to support their child in becoming an independent person ${ }^{46}$, a message relayed by many of the current study's participants. Finally, the fact that participants regarded good parents as role models is consistent with the literature with respect to the effects of modelling. ${ }^{47}$ 
Category 4, the ability to put your child's needs before your own, reflects a primary tenet within child protection. Parents are viewed as at risk of maltreating a child if they prioritise their own needs over their child's. ${ }^{48}$ The current research supports Hoghughi ${ }^{49}$, who argues that to be an effective parent, parents must be able to sacrifice personal needs, and protect the child.

Category 5, 'fostering attachment', indicates that engagement in behaviours and activities to enhance attachment reflects good parenting. This is consistent with contemporary literature on the fundamental importance of attachment for the healthy psychological and social development of a child. ${ }^{50}$ The finding that every participant recognised the need for parents to foster attachment with their child is promising, indicating that their opinions and thus professional practice may be, to some extent, evidence-based.

The final category, 'consistency versus flexibility', is also in keeping with extant literature on parenting. Consistency ${ }^{22}$ and boundary setting ${ }^{35}$ have previously been identified by health professionals as key dimensions of 'good enough’ parenting. This study's finding of flexibility as a key dimension of good parenting, supports Azar and Cote ${ }^{30}$, who argue that a parent's flexibility should be a key dimension when assessing culturally diverse clients. It is also consistent with the term, competent parenting, relating to a parent's ability to adapt to the changing developmental needs of a child. ${ }^{30}$ While these two constructs have been widely discussed within the parenting literature, the combination of consistency and flexibility as one dimension has not been included in parenting models to date.

\section{Theoretical and Practical Implications}

The results of the current study have important theoretical and practical implications. From a theoretical perspective, this study contributes to the literature on parenting, by proposing a theoretical model of professionals' opinions on good parenting. While none of 
the identified categories of good parenting are new, this is the first time they have been combined in such a way.

Suggestions have been made that clinical assessments of parents by mental health professionals may be incompatible with legal settings, due to fundamental differences in assumptions. ${ }^{9}$ However, the findings in this study suggest that generally, professionals from mental health and legal settings agree on the main aspects of good parenting. Nevertheless, the individual differences found even within professional groups exemplify the complex nature of parenting, and the unstandardised nature of clinical judgement in which individual values may affect decision making rather than professional standards.

Nonetheless, this study contributes to the parenting literature by identifying potential parental strengths that could be included in parenting capacity assessments, as opposed to the current focus on parental weaknesses. However, there were a number of limitations in the current study. First, the low consent rate (38\%) may have skewed results as those who refused to participate may have had a different perspective. Furthermore, of the lawyers, only 2 had experience with child protection and were predominantly family lawyers. Thus, their perspectives may not be representative of all lawyers, particularly of those in child protection. The lack of anonymity may have also influenced the participants' responses due to issues of social desirability. However, participants were reminded throughout that there was no right answer and that all responses would remain confidential.

Furthermore, due to the nature of interviewing, the participants' responses may have been influenced by the interview questions. However, since the study was interested in the degree of agreement between professionals, it was determined that all participants needed to address the same broad questions. To limit the influence of the researcher, the broad areas of parenting were prompted only after sufficient chance was given to the interviewees to identify them independently. Participants were also encouraged to talk about other areas not 
identified in the interview questions. A further limitation is that predominantly white, middleclass views on good parenting were surveyed. While all but 1 participant had worked with culturally diverse clients, the findings may not generalise to 'good parents' from minority groups, or lower socioeconomic groups. For example, the finding that professionals believed that good parents encourage a child's independence reflects a Western value which may not be encouraged in cultures where collectivism is esteemed. Even so, these findings are still of interest in understanding Western professionals’ conceptions of good parenting.

In addition, participants only had professional experience with struggling parents and thus the categories of good parenting are in relation to struggling parents rather than all parents in general. Even so, this information is relevant to forming a more comprehensive parenting capacity assessment, which deals with poor parenting. Furthermore, this research may be helpful in developing intervention programs for struggling parents, with a focus on developing aspects of good parenting, such as insight.

The use of GT relies heavily on the researchers' interpretation of the data, and thus results of this study are at risk of being influenced by the researcher's personal bias. However, constructivist GT openly acknowledges the inevitable role of the researcher, arguing that the theory developed is merely the researcher's interpretation of events. ${ }^{36}$ Even so, certain techniques were used to ensure rigour in this study. In order to limit such bias, the researchers kept a reflexive journal throughout the study questioning personal thoughts and values. This reflexive stance enabled the researchers to maintain a fresh perspective in order to produce the most fitting theory. In addition, rigour was establishing by ensuring the appropriateness of data (via theoretical sampling), and the adequacy of data (via theoretical sampling until the point of saturation), as recommended by Morse. ${ }^{51}$ The validity of the findings were enhanced by the triangulation of results. ${ }^{52}$ 


\section{Future directions}

Since parents from minority groups and lower socioeconomic groups are overrepresented in child protection cases ${ }^{1}$, future research needs to investigate conceptions of good parenting from their perspective. Furthermore, in order to extend this theoretical model, qualitative research should be conducted with professionals who have had experience with good parents (rather than struggling parents), such as those who conduct adoption assessments.

The fact that professionals generally agreed on aspects of good parenting is promising. The categories of good parenting found in this study, provides the basis for future quantitative research into the development of standard parental strengths in parenting capacity assessments. A large scale study, using a method such as structural equation modelling should investigate the validity of these categories and their relationship to one another. Based on this study, the expected relationships are as outlined in Figure 1. Future quantitative research may confirm these relationships, and this in turn may lead to the development of standard parental strengths to be included in all parenting capacity assessments. These categories could also inform the development of future parenting training programs in prevention or intervention.

\section{INSERT FIGURE 1 ABOUT HERE}

\section{Conclusion}

This study found that in general, professionals agree on what constitutes good parenting, supporting the legal applicability of clinical assessments of parents. This research provides a theoretical basis for future research to determine a set of standard parental strengths to be included in parenting capacity assessments and parenting training programs. This, in turn, may enhance the validity of significant decisions in relation to parents and their children. 


\section{References}

1. White, A. (2005). Literature review: Assessment of parenting capacity. Ashfield, Australia: Centre for Parenting \& Research.

2. Rutherford, S. J., \& Keeley, P. (2009). Assessing parenting capacity: Are mental health nurses prepared for this role? Journal of Psychiatric and Mental Health Nursing, 16(4), 363-367.

3. Condie, L. O. (2003). Parenting evaluations for the court: care and protection matters. New York: Kluwer Academic/Plenum Publishers.

4. Waller, E. M., \& Daniel, A. E. (2005). Purpose and utility of child custody evaluations: The attorney's perspective. Journal of the American Academy of Psychiatry and the Law, 33(2), 199-207.

5. Connell, M. (2008). Changes in the wind: Parenting assessment in family dissolution matters. Journal of Psychiatry and Law, 36(1), 9-40.

6. Hart, D. (Ed.). (2010). Assessment before birth. London: Jessica Kingsley Publishers.

7. Budd, K. S., Poindexter, L. M., Felix, E. D., \& Naik-Polan, A. T. (2001). Clinical assessment of parents in child protection cases: An empirical analysis. Law and Human Behavior, 25(1), 93-108.

8. Azar, S. T., Lauretti, A. F., \& Loding, B. V. (1998). The evaluation of parental fitness in termination of parental right cases: A functional-contextual perspective. Clinical Child and Family Psychology Review, 1(2), 77-100.

9. Budd, K. S., Poindexter, L. M., Felix, E. D., \& Naik-Polan, A. T. (2001). Clinical assessment of parents in child protection cases: An empirical analysis. Law and Human Behavior, 25(1), 93-108. 
10. Lennings, C. (2002). Decision making in care and protection: The expert assessment. Australian e-Journal for the Advancement of Mental Health, 1(2).

11. Jamieson, N., Tranah, T., \& Sheldrick, E. C. (1999). The impact of expert evidence on care proceedings. Child Abuse Review, 8(3), 183-192.

12. American Psychological Association Committee on Professional Practice and Standards. (1998). Guidelines for psychological evaluations in child protection matters. Washington: American Psychological Association.

13. Department of Health, Department for Education Employment, \& Home Office. (2000). Framework for the assessment of children in need and their families. London: The Stationery Office.

14. Steinhauer, P. D. (1983). Assessing for parenting capacity. American Journal of Orthopsychiatry, 53(3), 468-481.

15. Budd, K. S., \& Holdsworth, M. J. (1996). Issues in clinical assessment of minimal parenting competence. Journal of Clinical Child Psychology, 25(1), 1-14.

16. Mrazek, D. A., Mrazek, P., \& Klinnert, M. (1995). Clinical assessment of parenting. Journal of the American Academy of Child and Adolescent Psychiatry, 34(3), 272282.

17. Sommerfeld, D. P., \& Hughes, J. R. (1987). Do health professionals agree on the parenting potential of pregnant women? Social Science \& Medicine, 24(3), 285-288.

18. Baird, C., \& Wagner, D. (2000). The relative validity of actuarial and consensusbased risk assessment systems. Children and Youth Services Review, 22(11-12), 839871.

19. Shalonsky, A., \& Wagner, D. (2005). The next step: Integrating actuarial risk assessment and clinical judgement into an evidence-based practice framework in CPS case management. Children and Youth Services Review, 27(4), 409-427. 
20. Dawes, R. M., Faust, D., \& Meehl, P. E. (1989). Clinical vs. actuarial judgement. Science, 243(4899), 1668-1674.

21. Munro, E. (1999). Common errors of reasoning in child protection work. Child Abuse and Neglect, 23(8), 745-758.

22. Woodcock, J. (2003). The social work assessment of parenting: An exploration. British Journal of Social Work, 33(1), 87-106.

23. Daniel, B. (2000). Judgements about parenting: What do social workers think they are doing? Child Abuse Review, 9(2), 91-107.

24. Conley, C. (2003). A review of parenting capacity assessment reports. Ontario Association of Children's Aid Societies 47(3), 16-23.

25. Jones, D. (2010). Assessment of parenting. In J. Horwath (Ed.), The child's world: The comprehensive guide to assessing children in need (2nd ed., pp. 282-304). London: Jessica Kingsley Publishers.

26. Gambrill, E., \& Shlonsky, A. (2000). Risk assessment in context. Children and Youth Services Review, 22(11-12), 813-837.

27. Lennings, C. (2005). Risk assessment in care and protection: The case for actuarial approaches. Australian e-Journal for the Advancement of Mental Health, 4(1), 1-10.

28. Jacobsen, T., Miller, L. J., \& Kirkwood, K. P. (1997). Assessing parenting competency in individuals with severe mental illness: A comprehensive service. The Journal of Mental Health Administration, 24(2), 189-199.

29. Llewellyn, G., McConnell, D., Russo, D., Mayes, R., \& Honey, A. (2002). Homebased programmes for parents with intellectual disabilities: Lessons from practice. Journal of Applied Research in Intellectual Disabilities, 15(4), 341-353.

30. Azar, S. T., \& Cote, L. R. (2002). Sociocultural issues in the evaluation of the needs of children in custody decision making. What do our current frameworks for 
evaluating parenting practices have to offer? International Journal of Law and Psychiatry, 25(3), 193-217.

31. Baumrind, D. (1967). Child care practices anteceding three patterns of preschool behavior. Genetic Psychology Monographs, 75, 43-88.

32. Devore, E. R., \& Ginsburg, K.R. (2005). The protective effects of good parenting on adolescents. Current Opinion in Pediatrics, 17(4), 460-465.

33. Belsky, J., \& Vondra, J. (Eds.). (1989). Lessons from child abuse: The determinants of parenting. Cambridge: Cambridge University Press.

34. Farnfield, S. (2008). A theoretical model for the comprehensive assessment of parenting. British Journal of Social Work, 38(6), 1076-1099.

35. Taylor, J., Lauder, W., Moy, M., \& Corlett, J. (2009). Practitioner assessments of 'good enough' parenting: factorial survey. Journal of Clinical Nursing, 18(8), 11801189.

36. Charmaz, K. (2006). Constructing grounded theory: A practical guide through qualitative analysis. London: Sage Publications Ltd.

37. Strauss, A. L., \& Corbin, J. (1990). Basics of qualitative research: Grounded theory procedures and techniques. Newbury Park: Sage.

38. Pitcairn, T., Waterhouse, L., McGhee, J., Secker, J., \& Sullivan, C. (1993). Evaluating parenting in child physical abuse. In L. Waterhouse (Ed.), Child abuse and child abusers: Protection and prevention. London: Jessica Kingsley Publishers.

39. Rutter, M. (1985). Resilience in the face of adversity. Protective factors and resistance to psychiatric disorder. British Journal of Psychiatry, 147(6), 598-611.

40. Strauss, A. L., \& Corbin, J. 1997. Grounded Theory in Practice. Thousand Oaks: Sage. 
41. Mullick, M., Miller, L. J., \& Jacobsen, T. (2001). Insight into mental illness and child maltreatment risk among mothers with major psychiatric disorders. Psychiatric Services, 52(4), 488-492.

42. Holden, G. W., \& Hawk, C. K. (2003). Meta-parenting in the journey of child rearing: A cognitive mechanism for change. In L. Kuczynski (Ed.), Handbook of dynamics in parent-child relations (pp. 189-210). Thousand Oaks: Sage Publications Inc.

43. Donald, T., \& Jureidini, J. (2004). Parenting capacity. Child Abuse Review, 13(1), 517.

44. Tomison, A. M. (1998). Valuing parent education: A cornerstone of child abuse prevention. Child Abuse Prevention Issues, 10, 1-20. Retrieved September 18, 2010, from http://www.aifs.gov.au/nch/pubs/issues/issues10/issues10.html

45. Jacobson, A. L. (2004). Contemporary models for positive parenting. Journal of Family and Consumer Sciences, 96(4), 4-9.

46. Markus, H. R., \& Kitayama, S. (1991). Culture and the self: Implications for cognition, emotion, and motivation. Psychological Review, 98(2), 224-253.

47. Bandura, A. (1971). Social learning theory. New York: General Learning Press.

48. Department of Human Services. (2007). Child development and trauma guide. Retrieved September 20, 2010 from http://wcm.dhs.vic.gov.au/_data/assets/pdf_file/0009/449217/child-developmentand-trauma-guide.pdf

49. Hoghughi, M. (1997). Parenting at the margins: Some consequences of inequality. Chichester: Wiley.

50. Howe, D. (2010). Attachment: Implications for assessing children's needs and parenting capacity. In J. Horwath (Ed.), The child's world: The comprehensive guide 
to assessing children in need (2nd ed., pp. 184-198). London: Jessica Kingsley Publishers.

51. Morse, J. M. (Ed.). (1994). Designing funded qualitative research. London: Sage. 52. Gibson, B. (2007). Accomodating critical theory. London: Sage Publications Ltd. 
TABLE 1

Demographics of participants

\begin{tabular}{|c|c|c|c|c|c|c|c|c|c|}
\hline \multirow{2}{*}{$\begin{array}{l}\text { Profession } \\
\text { Social }\end{array}$} & \multirow[t]{2}{*}{$\begin{array}{l}\mathrm{n} \\
5\end{array}$} & \multicolumn{2}{|c|}{ Gender } & \multirow{2}{*}{$\begin{array}{l}\begin{array}{l}\text { Mean age } \\
\text { (range) }\end{array} \\
48.6\end{array}$} & \multirow{2}{*}{$\begin{array}{l}\text { Mean years } \\
\text { of } \\
\text { experience } \\
\text { (range) } \\
11\end{array}$} & \multicolumn{2}{|c|}{$\begin{array}{l}\text { Own } \\
\text { children }\end{array}$} & \multicolumn{2}{|c|}{$\begin{array}{l}\text { Work with } \\
\text { culturally } \\
\text { diverse } \\
\text { clients }\end{array}$} \\
\hline & & $F$ & 5 & & & Yes & 4 & Yes & 5 \\
\hline Worker/ CS & & $M$ & 0 & $(29-60)$ & $(2-30)$ & No & 1 & No & 0 \\
\hline \multirow[t]{2}{*}{ Psychologist } & 5 & $F$ & 2 & 44.8 & 15.4 & Yes & 3 & Yes & 5 \\
\hline & & $M$ & 3 & $(26-58)$ & $(2-32)$ & No & 2 & No & 0 \\
\hline \multirow[t]{2}{*}{$\overline{\text { Lawyer }}$} & 5 & $F$ & 4 & 40 & 11.6 & Yes & 5 & Yes & 5 \\
\hline & & $M$ & 1 & $(32-55)$ & $(5-28)$ & No & 0 & No & 0 \\
\hline \multirow[t]{2}{*}{ Magistrate } & 4 & $F$ & 1 & 66 & 11.5 & Yes & 4 & Yes & 3 \\
\hline & & $M$ & 3 & $(60-80)$ & $(5-20)$ & No & 0 & No & 1 \\
\hline \multirow[t]{2}{*}{ Total } & $\mathrm{N}=19$ & $F$ & 12 & 49 & 12.42 & Yes & 16 & Yes & 18 \\
\hline & & $M$ & 7 & $(26-80)$ & $(2-32)$ & No & 3 & No & 1 \\
\hline
\end{tabular}


TABLE 2

Professionals' opinions on the relative importance of different parenting dimensions

\begin{tabular}{|c|c|c|c|c|c|c|c|}
\hline $\begin{array}{c}\text { PROFESSIONAL } \\
\text { GROUP }\end{array}$ & PARTICIPANT & $\begin{array}{c}\text { PHYSICAL } \\
\text { CARE }\end{array}$ & $\begin{array}{c}\text { EMOTIONAL } \\
\text { CARE }\end{array}$ & $\begin{array}{c}\text { DEVELOP- } \\
\text { MENTAL } \\
\text { SUPPORT }\end{array}$ & $\begin{array}{c}\text { PHYSICAL \& } \\
\text { EMOTIONAL } \\
\text { CARE }\end{array}$ & $\begin{array}{c}\text { PHYSICAL, } \\
\text { EMOTIONAL } \\
\text { \& DEVELOP- } \\
\text { MENTAL }\end{array}$ & ALL \\
\hline \multirow{5}{*}{$\begin{array}{l}\text { Social Worker/ CS } \\
\text { Worker }\end{array}$} & 1 & & $\bigotimes$ & & & & \\
\hline & 2 & & & & & & \\
\hline & 3 & & & & & & \\
\hline & 4 & & & & $\bigotimes$ & & \\
\hline & 5 & & & & & & \\
\hline \multirow[t]{5}{*}{ Psychologist } & 6 & & & & & & \\
\hline & 7 & & & & & & \\
\hline & 8 & & & & & & \\
\hline & 9 & & & & & & \\
\hline & 10 & & & & & & \\
\hline \multirow[t]{5}{*}{ Lawyer } & 11 & & & & $\bar{\Delta}$ & & \\
\hline & 12 & & $\bigotimes$ & & & & \\
\hline & 13 & & & $\bigotimes$ & & & \\
\hline & 14 & $\triangle$ & & & & & \\
\hline & 15 & & $\bigotimes$ & & & & \\
\hline \multirow[t]{4}{*}{ Magistrate } & 16 & $\bigotimes$ & & & & & \\
\hline & 17 & & $\triangle$ & & & & \\
\hline & 18 & & & & & 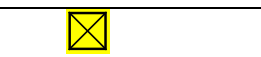 & \\
\hline & 19 & Х & & & & & \\
\hline
\end{tabular}

N.B. Parenting tasks identified by participants as the most important according to rating scale and interview responses (See Appendices C-D). From rating scale: 'Physical' classified as health, safety, and physical care; 'All' classified as health, safety, family \& social support, emotional, physical, cognitive, discipline, and developmental (see Appendix D for rating scale). 


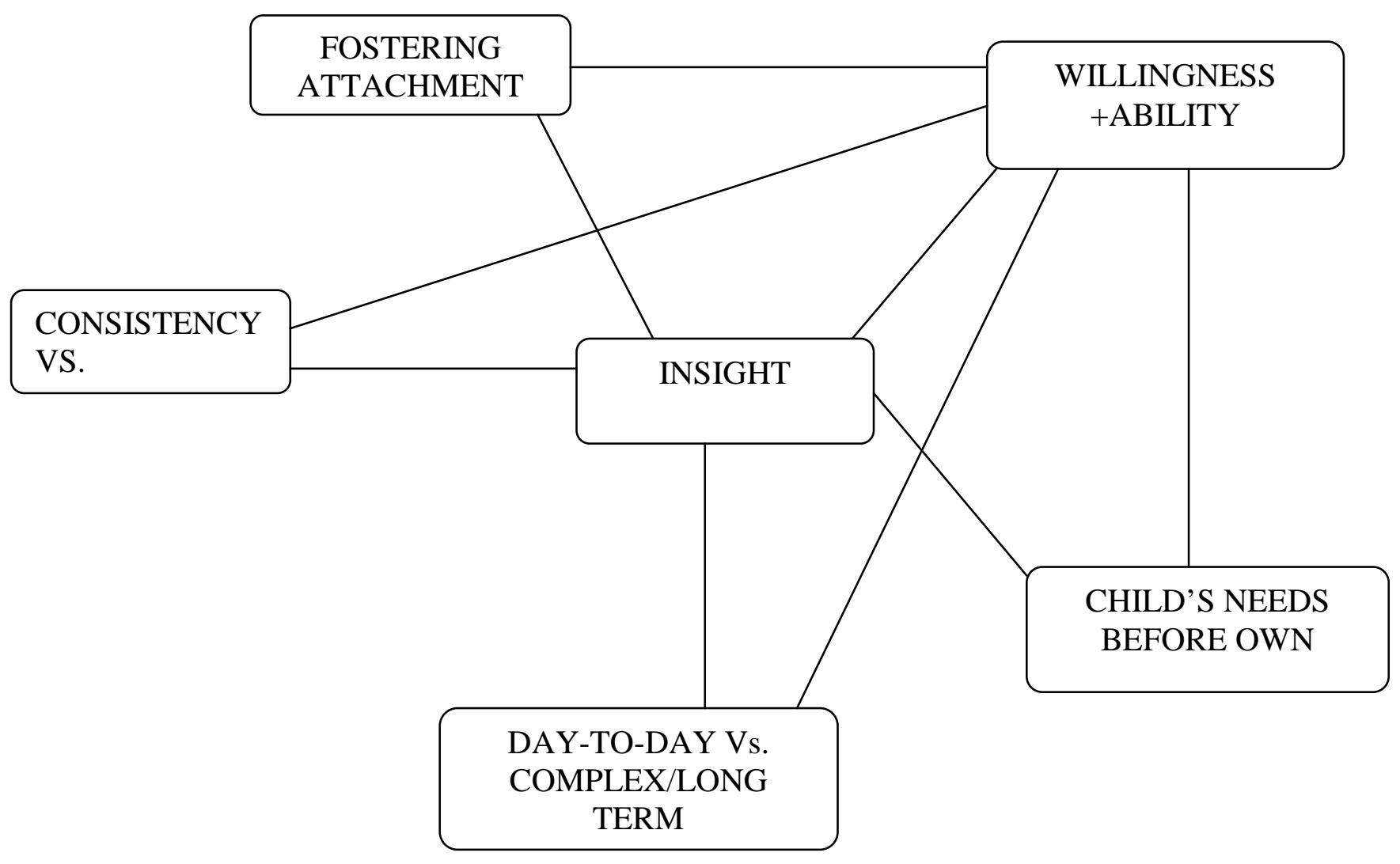

FIGURE 1

Six categories of good parenting identified by professionals 